Association for Information Systems

AIS Electronic Library (AISeL)

ICEB 2003 Proceedings

International Conference on Electronic Business

(ICEB)

Winter 12-9-2003

\title{
The Impacts of Establishing Enterprise Information Portals on e- Business Performance
}

Shu-Min Yang

Ming-Hsien Yang

Ji-Tsung Ben Wu

Follow this and additional works at: https://aisel.aisnet.org/iceb2003

This material is brought to you by the International Conference on Electronic Business (ICEB) at AIS Electronic Library (AISeL). It has been accepted for inclusion in ICEB 2003 Proceedings by an authorized administrator of AIS Electronic Library (AISeL). For more information, please contact elibrary@aisnet.org. 


\title{
The Impacts of Establishing Enterprise Information Portals on e-Business Performance
}

\author{
Shu-Min Yang, Ming-Hsien Yang, Ji-Tsung Ben Wu \\ Department of Information Management, College of Management \\ Fu-Jen Catholic University \\ Taiwan \\ yang@im.fju.edu.tw
}

\begin{abstract}
The Enterprise Information Portal (EIP) provides access - a single point of personalized, on-line access - to business information and knowledge sources, and real-time access to core application and processes. EIP is defined as an ultimate window that presents e-business fruitful results. Our research focuses on investigating the relationship between organizational characteristics and whether EIP is adopted in the business operations and the relationship among the function application degree, implementation type, integration ability, and users of EIP and e-Business performances. The result of our study shows that: (1) Between those organizations have and those have not adopted EIP, there are significant differences in the maturity and familiarity of information technologies, and organizational size; (2) In the way of implementation EIP, the relationship among function application degree, implementation type, integration ability, and e-Business performance are also significantly influence; (3) The impact between function application degree of EIP and e-Business performance will be enhanced by high e-business degree; (4) The impact between implementation type of EIP and e-Business performance will be intervened by e-business degree; (5) The implementation time of EIP has no significant impact on the relationship between implementation EIP and e-Business performance.
\end{abstract}

\section{Introduction}

The rapid developments of Internet and information technology not only provide great growth opportunities, but also change the way that enterprise operates and shaped the era of digital economy. The U.S. Census Bureau's e-Business Steering Committee divides the "electronic economy" into three layers: e-Business infrastructure, e-Business ("any process that a business organization conducts over computer-mediated network channels"), and e-commerce ("any transaction completed over a computer-mediated network that involves the transfer of ownership or rights to use goods or services") (Mesenbourg, 2000). As Gerstner (2000) indicated, "Today, e-Business is just Business - real business." Thus it can be seen e-Business will play an important role in digital economy to enhance competitive advantages.

Due to technology advances and the wide dissemination of information, many institutions suffer from information overload and need to apply information management to deal with this information chaos in this digital world. Furthermore, organizations increase the requirements of experience and knowledge sharing, system integration ability, and personalized. The Enterprise Information Portal (EIP) provides access - a single point of personalized, on-line access - to business information and knowledge sources, and real-time access to core application and processes. According to Shilakes \& Tylman (1998), Enterprise Information Portal is considered an emerging market opportunity, an amalgamation of software applications that consolidate, manage, analyze and distribute information across and outside of an enterprise (including business intelligence, content management, data warehouse/mart, and data management applications.)

Recently, industry trend-watchers have forecasted the rise of portal development in corporations. For instance, Gartner Group predicts with $80 \%$ probability that more than half of all major companies by the end of the year 2001 will implement corporate portals as the primary method for organizing and discovering corporate resources (Detler, 2000). Likewise, the Enterprise information Portal adoption rate based on a Delphi Group survey of Fortune 500 companies in 1999 . About $35 \%$ of these companies have implemented a corporate portal and another $30 \%$ are in the pilot/experimental stage of development (Aneja et al., 2000). Further, Shilakes \& Tylman (1999) estimate that the market for portal tools and services will be worth upwards of $\$ 14.8$ billion by the year 2002. Consequently, the Enterprise Information Portal is the most important business information management project of the next decade (Collins, 1999).

Our research focuses on investigating the relationship between organizational characteristics and whether EIP is adopted in the business operations and the relationship among the function application degree, implementation type, integration ability, and users of EIP and e-Business performances. Then, we address the e-Business degree and implementation time in intervening the influence of the impact of establishing EIP and e-Business performance.

\section{Related Research}

\subsection{Enterprise Information Portal}

Reynolds \& Koulopoulos (1999) identify four phases of web portal development: boolean search, categorized 
navigation, personalization and, finally, integration of additional features providing direct access to other specialized information and commercial worlds. This web portal evolution impressed the corporate community, which viewed the possibility to use the same technology to manage structure and facilitate the task of accessing the companies' internal information.

There has been a great interest during the past two years in the emergence of Enterprise Information Portal. In sum, an enterprise portal can be defined as a single point of access (SPOA) for the pooling, organizing, interacting, and distributing of organizational knowledge (Aneja et al., 2000; Schroeder, 2000).

Since newly developed, the terminology related to the Enterprise Information Portal has not been settled yet. The terms "corporate portal", "corporate information portal", "business portal", and "enterprise information portal" are used, some times, interchangeably as synonyms (Dias, 2000). Cutter Consortium also indicated Enterprise Information Portal is a "fuzzy word" (Chen, 2002).

Shilakes \& Tylman (1998) identified Enterprise Information Portal as an amalgamation of software applications consolidate, manage, analyze and distribute information across and outside of an enterprise and enable companies to unlock internally and externally stored to make informed business decisions. Eckerson (1999) uses another term "business portal" and defines it as an application that provides business users one-stop shopping for any information object they need inside or outside the corporation. Dias (2001) uses a term "corporate portal", closely related to EIP, and use technical point of view to identify corporate portal uses metadata and eXtensible Markup Language (XML) to integrate unstructured data to structured data from operational databases, supplying access to corporate information through a personalized interface, available over the internal hypertext network-The Intranet. On the other hand, Murray (1999) stated that portals that focus only on content are inadequate for the corporate market and that "corporate portals must connect us not only with everything we need, but with everyone we need, and provide all the tools we need to work together" (Murray, 1999).

Portals have fairly complex structures and features. According to survey results for Intelligent Enterprise readers, once deployed, EIP resources will be divided among these functions: B2B e-commerce(38\%), B2E e-commerce(37\%), B2C e-commerce(25\%) (Willen, 2000). However, their functions and elements are relatively easy to define (Roal et al., 2002). First, from an operational perspective, the strength of corporate portals lies in its ability to provide Web-based access to enterprise information, applications and processes. Second, from a functional perspective, they leverage existing information systems, data stores, networks, workstations, servers, and applications as well as other knowledge bases to give each employee in every corporate site immediate access to an invaluable set of corporate data anytime, anywhere (Kendler, 2000; White, 2000).
Functions and features are fairly difficult to define separately because they may have inter-related macro and micro level components. In most corporate portals, features and functions co-exist at the same level because they are still in the maturing process. Typically, the more common functions are the components that provide access to the range of disparate enterprise databases and information resources and the ease with which users can set up personalized access to enterprise and external information resources (White, 2000). In most enterprise portals, these functions may include, but are not limited to security, network, administrative tools, search, content management, collaboration personalization, extensibility, easy to use, and scalability (Eckerson, 2000).

\subsection{E-Business}

E-business is more than just an Internet presence or e-commerce transactions. It is a new business design "that emphasizes a finely tuned integration of customer needs, technology and processes" (Kalakota \& Robinson, 1999).

Kalakota \& Robinson (1999) define e-business as the complex fusion of business processes, enterprise applications, and organizational structure necessary to create a high-performance business model. e-Business includes e-commerce, as well as both front- and back-office applications that form the engine of modern business (Kalakota \& Robinson, 1999).

e-Business is an enterprise with the capability to exchange value (goods, services, money, and knowledge) digitally. It has properly designed business processes for this new way of conducting business. Further, it understands the human performance challenges not only within its organizational boundaries but also for other people in its enterprise network: customers, partners, and suppliers. e-Business is a new way of doing business that involves connectivity, transparency, sharing, and integration. It connects the expanded enterprise through a universal digital medium to partners, suppliers, and customers. It requires the integration and alignment of business processes, technology, and people with a continuously evolving e-business strategy (Hackbarth \& Kettinger 2000).

\subsection{Organizational Characteristics}

The organizational characteristics have significant impacts on quality and effectiveness of the planning process of information systems. The planning method of information systems must match the organizational characteristics (Premkumar \& King, 1994). The relationship between organizational characteristics and whether Information Technology is adopted has been emphasized in both empirical and prescriptive studies (Yap, 1990; Grover et al., 1993; Yap \& Thong, 1995; Premkumar \& King, 1994).

Thong \& Yap (1995) found that business size is the most significant discriminator in determining the use of information technology. Because here are some limitations for the small companies to adopt IT, such as 
poor resources, financial constraints, lack of specialists, and high sensibility to outside pressures. They also demonstrated that competitiveness in the environment and information intensity does not significantly influence the adoption of information technology by small businesses. Grover et al. (1995) found that organizational structure and centralization influence organizations to adopt telecommunication technology.

According to prior research, this paper conduct seven organization characteristics from related research, including business size, information intensity, formalization, centralization, the maturity and familiarity of information technologies, industry type, and competitiveness of environment.

\section{Research Method}

\subsection{Research Model}

The objectives of this study were to understand the relationship between organizational characteristics and whether Enterprise Information Portal is adopted in the business operations and the impact of e-Business performances when implementing Enterprise Information Portal. According to the research objectives and related researches and literatures, there are two phases of research model were shown in Fig. 1 and Fig. 2.

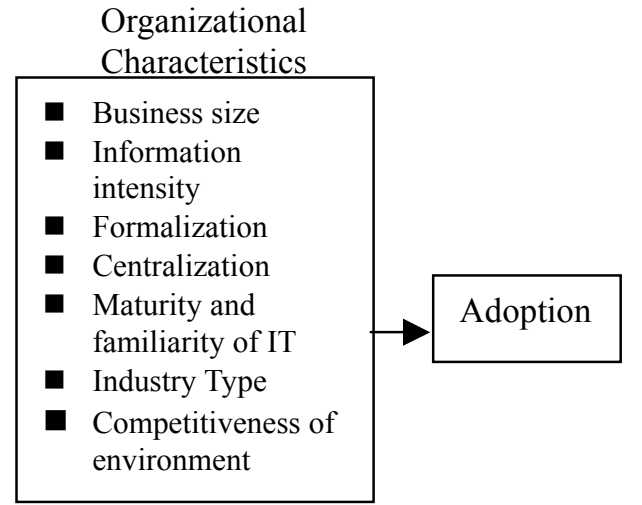

Fig. 1 Research Modal 2

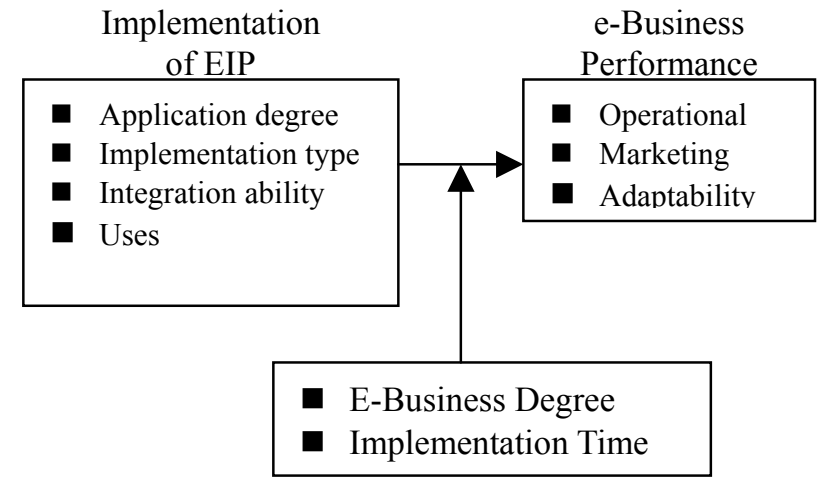

Fig. 2 Research model 1
In research model 1, we want to investigate the correlation between organization characteristics and the strategic decision to implement the Enterprise Information Portal. In independent variables, we induced seven organization characteristics from related research, including business size, information intensity, formalization, centralization, the maturity and familiarity of information technologies, industry type, and competitiveness of environment. The dependent variable, adoption, can be divided into two groups, adoption and non-adoption.

In research model 2, we would like to investigate the relationship among the implement of EIP and e-Business performances. Then, we address the e-Business degree and implementation time in intervening the influence of the impact of establishing EIP and e-Business performance. There are 4 directions to probe into the implement of EIP including application function degree, implementation type, integration ability, and users of EIP. In aspect of e-Business performance, we induced three different indicators from related literatures to measure, included operation performance, marketing performance, and adaptability performance. In intervening variable, the implementation time of EIP is different from each corporation, the time period my influence the e-Business performance. In addition, EIP is an important part of e-Business. Therefore, e-Business degree may influence the e-Business performance.

\subsection{Hypotheses}

The relationship between organizational characteristics and whether information technology is adopted has been emphasized in both empirical and prescriptive studies (Yap, 1990; Grover et al., 1993; Yap \& Thong, 1995; Premkumar \& King, 1994). According to the results of prior researches, organizational characteristics do significantly influence the adoption of information technology. The organizational characteristics have significant impacts on quality and effectiveness of the planning process of information systems. The planning method of information systems must match the organizational characteristics (Premkumar \& King, 1994). This leads to Hypothesis 1 (all hypotheses will be stated as null hypotheses):

H1: Organizational characteristics do not significantly influence the adoption of enterprise information portal.

We induced seven organization characteristics from related research, including business size, information intensity, formalization, centralization, the maturity and familiarity of information technologies, industry type, and competitiveness of environment. This leads to the following additional hypotheses: 
H1a: Business size does not significantly influence the adoption of EIP.

H1b: Information intensity does not significantly influence the adoption of EIP.

H1c: Formalize does not significantly influence the adoption of EIP.

H1d: Centralize does not significantly influence the adoption of EIP.

H1e: The maturity and familiarity of information technologies does not significantly influence the adoption of EIP.

H1f: Industry type does not significantly influence the adoption of EIP.

H1g: Competitiveness of environment does not significantly influence the adoption of EIP.

According to survey results by Chen (2002), applications functions of EIP do significantly influence on business performance. Consequently the stronger application function ability the corporations have, the corporation can more easily to achieve the requirements of increase ROI, enhance competitive advantages that the corporate needs. So, the stronger application function ability of EIP, the more brilliant e-Business performance. This leads to Hypothesis 2:

$\mathrm{H} 2$ : The application ability of EIP does not significantly influence the e-Business performance.

H2a: The application ability of EIP does not significantly influence the operation performance.

H2b: The application ability of EIP does not significantly influence the marketing performance.

H2c: The application ability of EIP does not significantly influence the adaptability performance.

The EIP product market is relatively young because it only stared in early 1998 (Raol et al, 2002). The market is very immature and it is crowded with venders offering different capabilities. Each product available on the EIP product market, when compared to its competitors has its own characteristics, distinct structure or additional components, presented as competitive (Dias, 2002).

White (1999) point out the two functions of EIP, decision-making support and collaborative processing, classifying EIP into four main categories: "Intranet Portal", "Collaborative Portal", "Decision Processing Portal", "e-Business Portal". It's the phases of EIP evolvement. An EIP begins to add real business value to an organization when it supports access to information managed by decision-processing systems. In Other word, in the phase of decision process portal, EIP start to add real business value to corporate and in the phase of e-Business portal, EIP can contribute the hugest business value to corporate. For the reason, different implement type of EIP may influence the business performance. This leads the Hypothesis 3:

H3: The implementation type of EIP does not significantly influence the e-Business performance.
H3a: The implementation type of EIP does not significantly influence the operation performance
$\mathrm{H} 3 \mathrm{~b}$ : The implementation type of EIP does not significantly influence the marketing performance
H3c: The implementation type of EIP does not significantly influence the adaptability performance

Application integration services enable EIP to provide users with a centralized, unified, and consistent environment for interactions with all applications (Hummingbird, 2000). As described by Shilakes \& Tylman (1998), central to the concept of Enterprise Information Portals is the assumption that disparate applications (content management, business intelligence, data warehouses/marts and data management) will :1) access other internal and external sources of information and data ,2) exchange information (bi-directional) and 3) use that information within the application for processing and analysis. In other words, these applications must be integrated with each other and to other external systems. The biggest selling point of EIP is their ability to present information from diverse sources through a common interface. Consequently, the most visible integration requirement for EIP is to provide an integrated web interface-based view of all (whether data store, content, or application server-based) of the information resources of the enterprise and external information resources that are the target of the EIP application (Joseph, 2001). This leads Hypothesis 4:

H4: The integration ability of EIP does not significantly influence the e-Business performance.

H4a: The integration ability of EIP does not significantly influence the operation performance.

H4b: The integration ability of EIP does not significantly influence the marketing performance

H4c: The integration ability of EIP does not significantly influence the adaptability performance

Besides employee, the user of EIP includes suppliers or partners and customers. EIP can Diver business advantages through real time collaboration among employee, customers, suppliers and partners. EIP users can be external users, such as suppliers, partners, and customers. It will promote business volume and operational performance. Therefore, the different users of 
EIP may influence the e-Business performance. This leads Hypothesis 5:

H5: The users of EIP do not significantly influence the e-Business performance.

H5a: The users of EIP do not significantly influence the operation performance.

H5b: The users of EIP do not significantly influence the marketing performance.

H5c: The users of EIP do not significantly influence the adaptability performance.

e-Business degree of organization is also the one of the factors may affect the e-Business performance. The successful implementation of the EIP is not only based on the business strategies that are tailored for the company, the corporation itself has also implemented e-Business in a satisfactory level. If the corporation still relies on traditional paper work culture, the competitiveness of the corporation will be decreased because of lack of informatics and digital technology. Furthermore, it will also create a barrier for the industry to launch and be one of the users of the prosperous internet, and it will not be able to gain all the benefits that the EIP can bring as a result. We therefore propose the following hypotheses:

H6: The impact between the implementation of EIP and e-Business performance will not be intervened by e-business degree.

H6a: The impact between application degree of EIP and e-Business performance will not be intervened by e-business degree.

H6b: The impact between the implementation type of EIP and e-Business performance will not be intervened by e-business degree.

H6c: The impact between the integration ability of EIP and e-Business performance will not be intervened by e-business degree.

H6d: The impact between the user of EIP and e-Business performance will not be intervened by e-business degree.

Furthermore, the implementation time of EIP is different from each organization, and the length of time will affect the performance. Base on the result of prior research, Chen (2000) mentioned the implementation time of IS has a significant impact on business performance. In other words, the longer time of the implement of system, the better business performance have. We therefore propose the following hypotheses:

H7: The impact between the implementation of EIP and e-Business performance will not be intervened by implementation time or EIP.

H7a: The impact between application degree of EIP and e-Business performance will not be intervened by implementation time or EIP.

H7b: The impact between the implementation type of EIP and e-Business performance will not be intervened by implementation time or EIP.

H7c: The impact between the integration ability of EIP and e-Business performance will not be intervened by implementation time or EIP.

H7d: The impact between the user of EIP and e-Business performance will not be intervened by implementation time or EIP.

\subsection{Sample and Data Collection}

The sample frame for this survey was constructed using stratified disproportionate random sampling from the list of Taiwan Top 1000 companies was furnished by Common Wealth Magazine. The survey includes data from finance, service and manufacture industry sampling 100, 300, 600 firms respectively as the sample for this study. The key informants were the IT senior managers.

\section{Analysis and Results}

\subsection{Data Collection}

1000 surveys were mailed to IT senior managers on Dec, 2002. A month after the first round mailing, reminders and follow-up questionnaires were mailed out to 883 non-responding firms. 192 surveys were returned and 181 had complete data usable for analysis, yielding an effective response rate of $18.1 \%$.

Among 181 respondents, 52 respondents indicated that they had completed an EIP deployment and 35 respondents were developing. They all start to implement EIP, so we classify $87(48 \%)$ respondents into adoption group. Another 50 respondents were still in the conceptual stage of EIP project, and 44 respondents have yet to plan and establish. We classify $94(52 \%)$ respondents into non-adoption group.

\subsection{Stability Test}

The non-response bias was tested in two ways. First, early and late respondents were compared upon four descriptive variables (e.g., industry type, turnover, total assets and employee numbers). The results of Chi-square test indicated that no significant differences in these four variables between early and late respondents ( $p$-value are $0.102,0.205,0.586,0.468)$. Thus, there was no evidence of obvious response bias in the sample.

Second, population and sample was compared upon three descriptive variables (e.g., industry type, total assets and employee numbers). The Chi-square test results also provides evidence that there was no non-response bias problem in the sample (p-values are $0.1845,0.429,0.072$ ).

\subsection{Validity \& Reliability Test}

Content validity is the determination whether the scale items used in the survey cover sufficient contents of the 
underlying constructs. Firstly, it was established through a careful assessment of the literature. Secondly, the pre-test is done by 3 EMBA students, and some refinements are done according to their suggestions. Finally, at each stage, the questionnaire is iteratively revised by experts in the MIS field.

Those items to represent a construct as a one-phase measurement model or a dimension as a two-phase measurement model must have the unidimensionality to make sure the total score is valid to measure a single concept. The items without the convergent validity should be eliminated, according to factor loadings.

In this study, we used Exploratory Factor Analysis (EFA) to test the construct validity of the measures and evaluate the factor loading. Principal component analysis with a Varimax rotation technique was conducted on all items and no restrictions were placed on the number of components to be extracted. The principal components were extracted on the basis of the "eigenvalues greater than 1" heuristic

In determining the appropriate minimum loadings required, loadings greater than .30 are considered significant; loadings of .40 are considered more significant; and loadings of .50 or greater are considered to be very significant. Thus, items were eliminated if the factor loading was below .50 .

Both the Bartlett Test of Sphericity, a statistical test for the presence of correlation, and Kaiser-Meyer-Olkin (KMO) measure of sampling adequacy are to determine the appropriateness of the factor analyses. Table 1 shows that KMO measures of sampling adequacy are higher than 0.725 , with accepted level above 0.5 , and the Bartlett test of Sphericity indicated significant differences in each construct, with p-value less than 0.05 , the model is statistically significant and further analysis could be conducted.

Table 1 KMO \& Bartlett test of sphericity

\begin{tabular}{|l|c|c|c|}
\hline \multirow{2}{*}{ Construct } & \multirow{2}{*}{$\begin{array}{c}\text { KMO Measure of } \\
\text { Sampling adequacy }\end{array}$} & Approx. Chi-Square & p-value \\
\cline { 3 - 4 } & 0.725 & 1488.760 & $0.000^{*}$ \\
\hline Organizational characteristic & 0.875 & 401.999 & $0.000^{*}$ \\
\hline Application ability & 0.900 & 1691.983 & $0.000^{*}$ \\
\hline Implementation feature & 0.861 & 592.938 & $0.000^{*}$ \\
\hline Integration degree & 0.891 & 2088.584 & $0.000^{*}$ \\
\hline e-Business degree & 0.884 & 661.550 & $0.000^{*}$ \\
\hline Operation performance & 0.725 & 336.933 & $0.000^{*}$ \\
\hline Marketing performance & 0.844 & 591.508 & $0.000^{*}$ \\
\hline Adaptability performance & \multicolumn{2}{c|}{. } \\
\hline
\end{tabular}

Cronbach's coefficient alpha is a widely used measure of scale reliability. Typically, a scale is reliable if $\alpha$ value is 0.7 or higher. Reliability tests were performed through the calculation of Cronbach's $\alpha$ for each construct. Besides one construct named information sharing which alpha value is 0.6933 slightly less then 0.7 . Others' alpha value ranged from 0.7067 to 0.9468 . Consequently, the result indicates internal consistency of the scales.

\subsection{Hypothesis Testing}

\subsubsection{The Relationship between Adoption EIP and Organizational Characteristic}

In the variables of organizational characteristic of the

Table 2 The relationship between organizational characteristic \& the adoption of EIP

\begin{tabular}{|l|c|c|c|c|c|}
\hline \multicolumn{1}{|c|}{$\begin{array}{c}\text { Organizational } \\
\text { Characteristic }\end{array}$} & \multirow{2}{*}{$\begin{array}{c}\text { Levene } \\
(\mathrm{p} \text {-value })\end{array}$} & Method & \multicolumn{2}{c|}{ Adoption EIP } & \multirow{2}{*}{ Result } \\
\cline { 4 - 5 } & & $\mathrm{F}\left(\mathrm{X}^{2}\right)$ & $\mathrm{p}$-value & \\
\hline Business size & $2.470(0.118)$ & ANOVA & 7.295 & $0.008^{*}$ & rejected \\
\hline Information intensity & $1.409(0.237)$ & ANOVA & 0.000 & 0.983 & not rejected \\
\hline Formalization & $0.481(0.489)$ & ANOVA & 0.411 & 0.522 & not rejected \\
\hline Centralization & $0.485(0.457)$ & ANOVA & 0.019 & 0.892 & not rejected \\
\hline $\begin{array}{l}\text { Maturity and } \\
\text { familiarity of IT }\end{array}$ & $2.655(0.105)$ & ANOVA & 21.061 & $0.000^{*}$ & rejected \\
\hline $\begin{array}{l}\text { Competitiveness of } \\
\text { environment }\end{array}$ & $0.045(0.832)$ & ANOVA & 0.496 & 0.482 & not rejected \\
\hline Industry type & - & Chi-square & $(2.781)$ & 0.245 & not rejected \\
\hline
\end{tabular}


The result of the one-way ANOVA and Chi-square test indicates that between those organizations have and those have not adopted EIP, there are significant differences in the "business size" and "maturity and familiarity of information technologies" ( $p<0.05)$. Thus, H1a and H1e are rejected. In addition, as show in Table 2, the correlation between other organizational characteristics included "information intensity", "formalization", "centralization", "industry type", and "competitiveness of environment" and adoption of EIP was not significant.
Therefore, H1b, H1c, H1d, H1f, H1g aren't rejected.

Moreover, in order to find the organizational characteristic which can totally explain the reason why corporate adopted the EIP technology, we used stepwise discriminate analysis to test. Table 3 shows, in sequence, the variable of organization characteristic in explaining why corporate adopted EIP is related to "maturity and familiarity of information technologies" and "business size".

Table 3 Stepwise discrimination analysis of organizational characteristic

\begin{tabular}{|l|l|c|c|c|}
\hline Order & Organizational Characteristic & F & $\begin{array}{c}\text { Wilk's } \\
\text { Lambda }\end{array}$ & $\begin{array}{c}\text { Standardized canonical } \\
\text { discriminat function coefficient }\end{array}$ \\
\hline 1 & Maturity and familiarity of IT & $21.061^{*}$ & 0.895 & 0.853 \\
\hline 2 & Business size & $12.389^{*}$ & 0.878 & 0.399 \\
\hline
\end{tabular}

\subsubsection{The Relationship between Implementation of EIP \& e-Business performance}

This study grouped application degree into high, medium, and low three categories based on the average score of the items, then analysis with e-Business, operational, marketing, and adaptability performance by ANOVA. It can be seen from the Table 4 that the hypothesis $\mathrm{H} 2$ is rejected for all performance indices.
Because we force to divide application degree into three group, its may reduce or enlarge the variability of application degree. This study tests the hypothesis again to ensure the result by stepwise regression analysis. As show in Table 5, the result is the same as ANOVA. Application degree of EIP does significantly influence the e-Business performance as well as three sub-construct of e-Business performance included operational, marketing, and adaptability performance.

Table 4 The result of application degree and e-Business performance

\begin{tabular}{|l|c|c|c|c|c|}
\hline \multicolumn{1}{|c|}{ Variables } & $\begin{array}{c}\text { Sum of } \\
\text { Squares }\end{array}$ & df & $\begin{array}{c}\text { Mean } \\
\text { Square }\end{array}$ & F & p-value \\
\hline E-Business performance & 12.971 & 2 & 6.486 & 14.800 & $0.000^{*}$ \\
\hline Operation performance & 13.690 & 2 & 6.845 & 14.832 & $0.000^{*}$ \\
\hline Marketing performance & 9.959 & 2 & 4.979 & 6.540 & $0.002^{*}$ \\
\hline Adaptability performance & 15.715 & 2 & 7.858 & 15.956 & $0.000^{*}$ \\
\hline
\end{tabular}

Table 5 Regression analysis of application degree and e-Business performance

\begin{tabular}{|l|c|c|c|c|c|}
\hline \multicolumn{1}{|c|}{ Variables } & Samples & $\mathrm{R}^{2}$ & $\beta$ & $\mathrm{t}$ & $\mathrm{p}$-value \\
\hline E-Business performance & 181 & 0.156 & 0.395 & 5.752 & $0.000^{*}$ \\
\hline Operation performance & 181 & 0.154 & 0.393 & 5.713 & $0.000^{*}$ \\
\hline Marketing performance & 181 & 0.082 & 0.286 & 3.995 & $0.000^{*}$ \\
\hline Adaptability performance & 181 & 0.155 & 0.394 & 5.737 & $0.000^{*}$ \\
\hline
\end{tabular}

In order to classify EIP into several types, this study employed the factory analysis according to its feature. Responses to the 17-items scales analyze by using a principal component analysis with a Varimax rotation through Exploratory Factor Analysis. The result extracted three factors solution of implementation features and named as follow: information application, information presentation and information sharing In all, the factor loading is greater than 0.5 level and accumulated percentage of variance is equal to $62.198 \%$.

To test $\mathrm{H} 3$, we grouped the respondents by conducting the cluster analysis on the score data of the feature factors, and then used the ANOVA to check if the average scores of the implementation features of different group of respondents are significantly different. We used the Ward's method, one of the hierarchical cluster methods, for the cluster analysis. The respondents were divided into three groups were 33 (18.7\%) low gradation EIP, 126 $(70 \%)$ developing EIP, and 21 (11.5\%) omnibearing EIP; they were so called because of the difference in their perceptions of the implementation feature factors.

Table 6 shows the results of the ANOVA of the scores of performance indices of the three groups of respondents. It can be seen from the table that $\mathrm{H} 3$ is rejected for the e-Business, operational, marketing, and adaptability performance. Therefore, the relationship between implementation type of EIP and e-Business performance has significantly influence. Omnibearing EIP type has high e-Business performance than other two types of EIP in evidence. 
Table 6 The result of implementation type and e-Business performance

\begin{tabular}{|l|c|c|c|c|c|c|}
\hline \multicolumn{1}{|c|}{ Variables } & $\begin{array}{c}\text { Sum of } \\
\text { Squares }\end{array}$ & df & $\begin{array}{c}\text { Mean } \\
\text { Square }\end{array}$ & F & p-value & Scheffe \\
\hline E-Business performance & 14.628 & 2 & 7.814 & 14.628 & $0.000^{*}$ & $\mathrm{~A} 3>\mathrm{A} 2, \mathrm{~A} 1$ \\
\hline Operation performance & 14.625 & 2 & 7.312 & 14.625 & $0.000^{*}$ & $\mathrm{~A} 3>\mathrm{A} 2, \mathrm{~A} 1$ \\
\hline Marketing performance & 18.480 & 2 & 9.240 & 18.480 & $0.000^{*}$ & $\mathrm{~A} 3>\mathrm{A} 2, \mathrm{~A} 1$ \\
\hline Adaptability performance & 14.569 & 2 & 7.284 & 14.589 & $0.000^{*}$ & $\mathrm{~A} 3>\mathrm{A} 2, \mathrm{~A} 1$ \\
\hline
\end{tabular}

Ps. A1: low gradation EIP; A2: developing EIP; A3: omnibearing EIP.

As well as application degree, this study grouped integration ability into high, medium, and low three categories based on the average score of the items, then analysis with e-Business, operational, marketing, and adaptability performance by ANOVA. It can be seen from the Table 7 that the hypothesis $\mathrm{H} 4$ is rejected for all performance indices.
Because we forced to divide grouped integration ability into three groups, it may reduce or enlarge the variability of grouped integration ability. This study tested the hypothesis again to ensure the result by stepwise regression analysis. Through Table 8 , the result of the correlation of integration ability and e-Business performance is significant as well.

Table 7 The result of integration ability and e-Business performance

\begin{tabular}{|l|c|c|c|c|c|}
\hline \multicolumn{1}{|c|}{ Variables } & $\begin{array}{c}\text { Sum of } \\
\text { Squares }\end{array}$ & df & $\begin{array}{c}\text { Mean } \\
\text { Square }\end{array}$ & F & p-value \\
\hline E-Business performance & 16.702 & 2 & 8.351 & 20.014 & $0.000^{*}$ \\
\hline Operation performance & 16.460 & 2 & 8.230 & 18.456 & $0.000^{*}$ \\
\hline Marketing performance & 14.783 & 2 & 7.391 & 10.066 & $0.000^{*}$ \\
\hline Adaptability performance & 19.011 & 2 & 9.505 & 20.056 & $0.000^{*}$ \\
\hline
\end{tabular}

Table 8 Regression analysis of application degree and e-Business performance

\begin{tabular}{|l|c|c|c|c|c|}
\hline \multicolumn{1}{|c|}{ Variables } & Samples & $\mathrm{R}^{2}$ & $\beta$ & $\mathrm{t}$ & $\mathrm{p}$-value \\
\hline E-Business performance & 181 & 0.251 & 0.501 & 7.739 & $0.000^{*}$ \\
\hline Operation performance & 181 & 0.243 & 0.493 & 7.589 & $0.000^{*}$ \\
\hline Marketing performance & 181 & 0.131 & 0.361 & 5.185 & $0.000^{*}$ \\
\hline Adaptability performance & 181 & 0.247 & 0.497 & 7.665 & $0.000^{*}$ \\
\hline
\end{tabular}

On the based of 52 respondents had completed an EIP deployment. The users of EIP ware divided into employee, partners/suppliers, and customers. As show in Table 9, H5 is not rejected. Hence, whatever the user type, the Impacts of Establishing Enterprise Information Portal on e-Business Performance do not significantly influence.

Table 9 The result of user of EIP and e-Business performance

\begin{tabular}{|l|c|c|c|c|c|}
\hline \multicolumn{1}{|c|}{ Variables } & $\begin{array}{c}\text { Sum of } \\
\text { Squares }\end{array}$ & df & $\begin{array}{c}\text { Mean } \\
\text { Square }\end{array}$ & F & p-value \\
\hline E-Business performance & 1.480 & 2 & 0.627 & 1.229 & 0.235 \\
\hline Operation performance & 1.928 & 2 & 0.803 & 1.232 & 0.226 \\
\hline Marketing performance & 1.918 & 2 & 0.757 & 0.876 & 0.325 \\
\hline Adaptability performance & 1.501 & 2 & 0.794 & 1.530 & 0.238 \\
\hline
\end{tabular}

\subsubsection{The Intervening Variable of e-Business Degree}

To test the impact between the implementation of EIP and e-Business performance if be intervened by e-business degree, this study grouped e-Business degree into high, medium, and low three categories based on the average score of the items. We verify the hypothesis by two-way ANOVA. If the result is significant, we go a step further to confirm the intervention is to enhance or weaken the impact by the graph of curve.

Table 10 demonstrates the impact between the implementation of EIP and e-Business performance is intervened by e-business degree. H6a is rejected. Fig.3 illustrates the interaction of application degree and e-Business degree. Whether the level of application degree is, high e-business degree has higher e-business performance than others. For this reason, we can infer the intervention is enhancing the impact between the implementation of EIP and e-Business performance. Furthermore, the curve line of low e-Business degree is not in common with others, especially in medium application degree. This is because in the group of medium application degree and low e-Business degree, among total 8 respondents, only one corporation was developing EIP. 3 corporations were still in the conceptual stage of EIP project, and other 4 respondents have yet to plan and establish. They all completely accomplish the 
implementation of EIP to lead to the bias of the result.

Table 10 The interaction between application degree and e-Business degree

\begin{tabular}{|c|l|c|c|c|c|}
\hline \multirow{2}{*}{ Source of Variance } & \multicolumn{1}{|c|}{ Variables } & $\begin{array}{c}\text { Sum of } \\
\text { Squares }\end{array}$ & df & $\begin{array}{c}\text { Mean } \\
\text { Square }\end{array}$ & F \\
\hline \multirow{2}{*}{$\begin{array}{c}\text { Application degree } \\
*\end{array}$} & E-Business performance & 7.169 & 1.792 & 5.113 & $0.001^{*}$ \\
\cline { 2 - 6 } e-Business degree & Operation performance & 8.909 & 2.227 & 5.722 & $0.000^{*}$ \\
\cline { 2 - 6 } & Marketing performance & 7.218 & 1.805 & 2.737 & $0.030^{*}$ \\
\cline { 2 - 6 } & Adaptability performance & 6.508 & 1.642 & 4.061 & $0.004^{*}$ \\
\hline
\end{tabular}

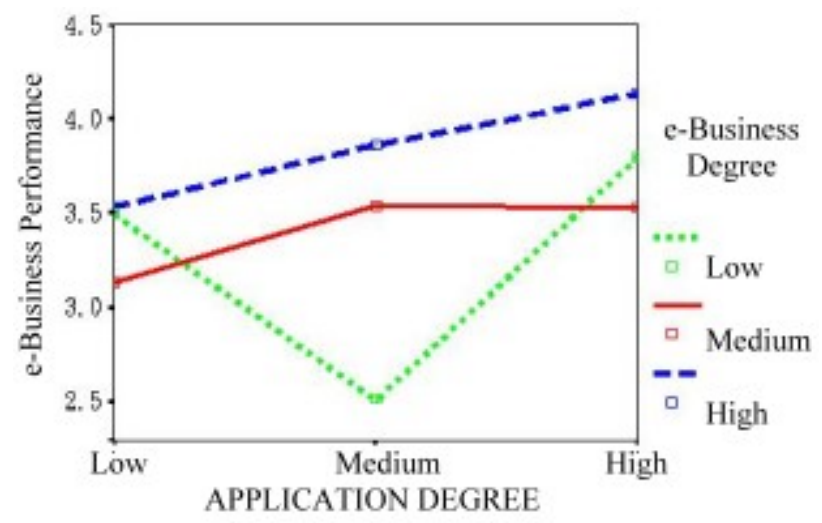

Fig. 3 Application degree and e-Business degree interact on e-Business performance

For the sake of accuracy of the result, we test the hypothesis again based on 52 samples had completed an EIP deployment. It can be seen from the Table 11 that the hypothesis H6a is rejected as well. As show in Fig. 4, high e-business degree has higher e-business performance than others consistently. The curve of line of low e-Business degree is also different. The bias is formed on account of the low application degree only has three samples and high application degree just has one sample, in low e-business degree group.

Table 11 The interaction between application degree and e-Business degree $(n=52)$

\begin{tabular}{|c|l|c|c|c|c|}
\hline \multirow{2}{*}{$\begin{array}{c}\text { Source of Variance } \\
\text { Application degree }\end{array} * \begin{array}{c}\text { Vum of } \\
*\end{array}$} & Squares & df & $\begin{array}{c}\text { Mean } \\
\text { Square }\end{array}$ & F \\
\cline { 2 - 6 } & E-Business performance & 2.424 & 0.808 & 2.942 & $0.043^{*}$ \\
\cline { 2 - 6 } e-Business degree & Operation performance & 5.295 & 1.765 & 5.299 & $0.003^{*}$ \\
\cline { 2 - 6 } & Marketing performance & 4.307 & 1.436 & 2.636 & 0.061 \\
\cline { 2 - 6 } & Adaptability performance & 0.332 & 0.111 & 0.279 & 0.840 \\
\hline
\end{tabular}

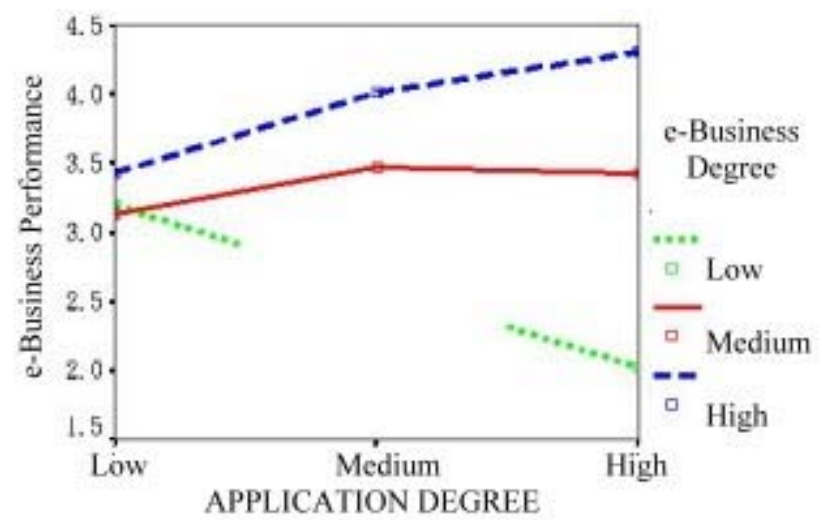

Fig. 4 Application degree and e-Business degree interact on e-Business performance $(\mathbf{n}=52)$

By two-way ANOVA, the impact between implementation type of EIP and e-Business performance will be intervened by e-business degree $(F=2.549, \mathrm{p}<0.05)$, as show in Table 12. Therefore, H6b is rejected.
According to the graph illustrates the interaction of implementation type and e-business degree on e-Business performance, with the exception of omnibearing type of EIP, high e-Business degree has higher e-Business 
performance approximately. On omnibearing type of EIP, lower e-Business degree corporations have highest e-Business performance than higher e-Business degree corporations instead because of this group is only has one sample. It raised the result of e-Business performance.

Table 12 The interaction between implementation type and e-Business degree

\begin{tabular}{|c|l|c|c|c|c|}
\hline \multirow{2}{*}{ Source of Variance } & Variables & $\begin{array}{c}\text { Sum of } \\
\text { Squares }\end{array}$ & df & $\begin{array}{c}\text { Mean } \\
\text { Square }\end{array}$ & F \\
\hline \multirow{2}{*}{$\begin{array}{c}\text { Implementation type } \\
*\end{array}$} & E-Business performance & 3.469 & 0.867 & 2.549 & $0.041^{*}$ \\
\cline { 2 - 6 } & Operation performance & 3.908 & 0.977 & 2.446 & $0.048^{*}$ \\
\cline { 2 - 6 } e-Business degree & Marketing performance & 5.078 & 1.269 & 2.099 & 0.083 \\
\cline { 2 - 6 } & Adaptability performance & 2.973 & 0.743 & 1.812 & 0.129 \\
\hline
\end{tabular}

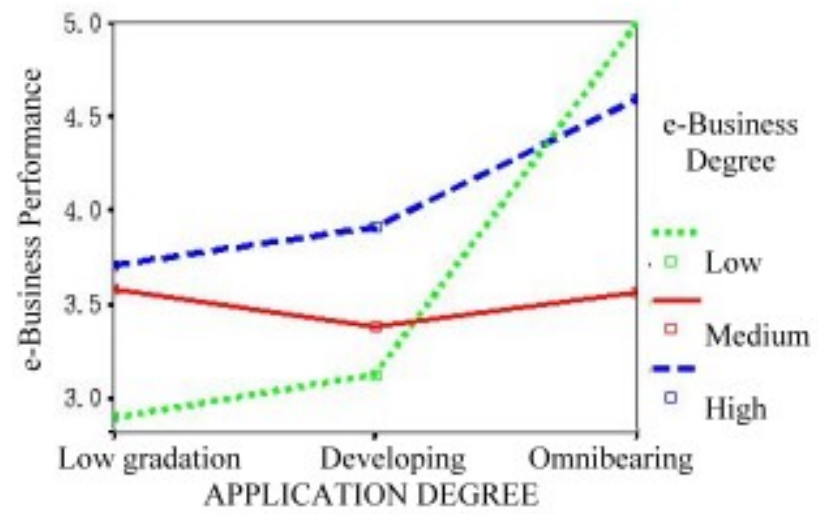

Fig. 5 Implementation type and e-Business degree interaction on e-Business performance

\section{Conclusion}

The result of our study shows that: (1) Between those organizations have and those have not adopted EIP, there are significant differences in the maturity and familiarity of information technologies, and organizational size; (2) In the way of implementation EIP, the relationship among function application degree, implementation type, integration ability, and e-Business performance are also significantly influence; (3) The impact between function application degree of EIP and e-Business performance will be enhanced by high e-business degree; (4) The impact between implementation type of EIP and e-Business performance will be intervened by e-business degree; (5) The implementation time of EIP has no significant impact on the relationship between implementation EIP and e-Business performance.

The most important reason corporations adopt EIP is "the maturity and familiarity of IT". Thus it can be seen EIP is a new concept of information management, the more IT implementation experiences, and the easier accept the new application system. Secondly, "business size" is another factor influence corporations adopt EIP, In general, the larger size of corporation, the requirement of information is more complex. Moreover, the cost of adopting new information technology must be expansive. The larger corporation may be more possible to implementation or prepare to start EIP project.

According to the result, more than half corporations implement EIPs since last two years. 52 respondents indicated that they had completed an EIP deployment and 35 respondents were developing. They all start to implement EIP, so we classify $87(48 \%)$ respondents into adoption group. Another 50 respondents were still in the conceptual stage of EIP project, and 44 respondents have yet to plan and establish. More than three fourth corporations had implemented EIP or started to plan EIP project. Thus it can be seen that EIP is available concept and the current trend of information management and e-Business project.

We divided EIP into three types: "low gradation EIP", "developing EIP”, “omnibearing EIP". Only $10 \%$ corporations belong to omnibearing EIP, 70\% corporations belong to developing EIP. It shows the implementation of EIP is immature.

The most important feature of EIP is easy to use and the users increase the familiar of internet environment. For users, EIP has more usability than other e-Business project. For corporations, the difficulty to train users to use EIP is lower the other e-Business performance.

(References are omitted due to page length limitation) 